\title{
THE PRECIPITATION AND IGNITION OF MAGNESIUM AMMONIUM PHOSPHATE
}

\author{
By J. I. Hoffman and G. E. F. Lundell
}

\section{ABSTRAC'T}

Conditions that are necessary for the precipitation and ignition of magnesium ammonium phosphate, $\mathrm{MgNH}_{4} \mathrm{PO}_{4} \cdot 6 \mathrm{H}_{2} \mathrm{O}$, in determinations of phosphorus or magnesium are described, and the temperatures at which the precipitates should be heated to obtain the most reliable results have been determined. In addition, observations on the temperatures of platinum crucibles heated over Tirrill, Méker, or Fischer burners with the same gas are reported, as well as observations on the losses in weight of platinum crucibles at different temperatures.

\section{CONTENTS}

II. Determination of phosphorus

1. Preparation of a standard solution of silver phosphate_._._. 280

(a) Tests for purity of the reagents and of silver phosphate_ 281

2. Analysis of silver phosphate... 281

(a) Determination of silver as chloride 281

(b) Determination of phosphorus by the pyrophosphate method (recommended procedure)

(1) Solubility of magnesium ammonium phosphate in the determination of phosphorus...-

(2) Ignition of magnesium ammonium phosphate in the determination of phosphorus....

III. Determination of magnesium
1. Preparation of a solution of magnesium chloride

2. Standardization of the solution of magnesium chloride.-..-

(a) Determination of magnesium by weighing as the oxide_

(b) Determination of magnesium by weighting as the sulphate.

(c) Determination of magnesium by weighing as the pyrophosphate (recommended procedure) _.......

(1) Solubility of magnesium ammonium phosphate in the determination of magnesium

(2) Ignition of magnesium ammonium phosphate in the determination of magnesium .....

IV. Summary

\section{INTRODUCTION}

In 1825 Berzelius ${ }^{1}$ mentioned magnesium ammonium phosphate, $\mathrm{MgNH}_{4} \mathrm{PO}_{4} \cdot 6 \mathrm{H}_{2} \mathrm{O}$, as a very insoluble substance. Since that time the compound has been extensively used in determinations of magnesium and of phosphorus. In either case the precipitate is usually ignited and weighed as magnesium pyrophosphate, $\mathrm{Mg}_{2} \mathrm{P}_{2} \mathrm{O}_{7}$. The vast amount of literature indicates that there is some conflict of opinion concerning the conditions necessary to obtain a precipitate which, when ignited, will yield a compound exactly conforming to the formula, $\mathrm{Mg}_{2} \mathrm{P}_{2} \mathrm{O}_{7}$. 
The present investigation was undertaken in order to determine these conditions by analyzing specially prepared solutions which contained known amounts of phosphorus in the one case and magnesium in the other. Special attention was given to the temperatures at which the precipitates were ignited. The effects of different amounts of ammonium hydroxide and ammonium chloride have been so completely discussed by Gooch and Austin, ${ }^{2}$ by Epperson ${ }^{3}$ and others that they need not be taken up here. Only the simple procedures which have been found to give accurate results will be discussed.

\section{DETERMINATION OF PHOSPHORUS}

Gooch and Austin used recystallized disodium hydrogen phosphate as the phosphorus standard in their work on the effect of ammonium hydroxide and ammonium salts. Epperson found very good agreement between the results for phosphorus obtained by a double precipitation as magnesium ammonium phosphate and those obtained by a method in which the phosphorus was precipitated as silver phosphate, the latter being taken as the standard. McCandless and Burton $^{4}$ recommended the use of microcosmic salt, $\mathrm{NaNH}_{4} \mathrm{HPO}_{4} \cdot 4 \mathrm{H}_{2} \mathrm{O}$, as a standard. In the present work it was deemed desirable to start with pure silver phosphate as a fundamental standard because Baxter and Jones ${ }^{5}$ have shown that this salt can be easily prepared in a perfectly definite and pure state.

\section{PREPARATION OF A STANDARD SOLUTION OF SILVER PHOSPHATE}

The method given by Baxter and Jones for the preparation o their samples $\mathrm{N}$ and $\mathrm{O}$, was employed for the preparation of the silver phosphate in the present work. ${ }^{6}$ The precipitates (corresponding to samples $\mathrm{N}$ and $\mathrm{O}$ ) were transferred to large platinum dishes and washed at least twenty times by decantation with distilled water. The washing was continued over a period of 40 hours in order to allow ample time for the leaching of all soluble matter. After draining the precipitates as much as possible on papers they were transferred to tubulated platinum crucibles and ignited to constant weight at $450^{\circ}$ to $500^{\circ} \mathrm{C}$. A stream of dry, purified air

2 F. A. Gooch and Martha Austin, Chem. News, 79, p. 255; 1899.

3 Alice Whitson Epperson, J. Am. Chem. Soc., 50, p. 321; 1928.

4 J. M. McCandless and J. I. Burton, Ind. Eng. Ćhem., 16, p. 1267; 1924; 19, p. 406; 1927.

5 G. P. Baxter and G. Jones, J. Am. Chem. Soc., 32, p. 298; 1910.

o'This method is as follows:

"A 0.03 normal solution of silver nitrate was slowly poured into a 0.03 normal solution of disodium hydrogen phosphate with frequent shaking. This reaction may be roughly considered to take place in two stages represented by the equations:

$$
\begin{aligned}
& 3 \mathrm{AgNO}_{3}+2 \mathrm{Na}_{2} \mathrm{HPO}_{4}=\mathrm{Ag}_{3} \mathrm{PO}_{4}+\mathrm{NaH}_{2} \mathrm{PO}_{4}+3 \mathrm{NaNO}_{3} \\
& 3 \mathrm{AgNO}_{3}+\mathrm{NaH}_{2} \mathrm{PO}_{4}=\mathrm{Ag}_{3} \mathrm{PO}_{4}+\mathrm{NaNO}_{3}+2 \mathrm{HNO}_{3}
\end{aligned}
$$

"At the beginning of the precipitation the solution is very slightly alkaline, and remains very nearly neutral during the addition of the first half of the silver nitrate. The concentration of the silver ion is lept very low by the excess of phosphate, and therefore little occlusion of the acid salts is to be expected in spite of the fact that the solution contains appreciable concentrations of the monohydrophosphate and dihydrophosphate ions. The precipitate during this stage is very finely divided and doesnot settle well, and therefore no attempt was made to collect it separatcly.

"During the addition of the second half of the silver nitrate the solution becomes slightly acid and the solubility of the silver phosphate increases rapidly. The precipitate settles readily. During the second stage the conditions are more favorable for the occlusion of the acid phosphate, but only a small amount of silver phosphate is precipitated during this stage.

"After standing a short time the mother liquor was decanted from the precipitate (sample N), and exactly the calculated amount of redistilled ammonia, diluted to 1 liter, was added to neutralize the excess of acid and comple te the precipitation. Since this sample (sample $\mathrm{O}$ ) was cvidently produced frota a solutiou which was slightly acid at the beginning of the precipitation, although very nearly neutral at the end, and since it contained a considerable amount of silver, the conditions were favorable for the formation of acid salts." 
was passed over the silver phosphate during the ignition. After the samples had been cooled in a desiccator over sulphuric acid, portions of each were taken and the silver determined as chloride. The results checked exactly. The two samples of silver phosphate were accordingly combined and used for preparing the standard solution.

The composite sample $(9.5057 \mathrm{~g})$ was dissolved in $100 \mathrm{ml}$ of dilute nitric acid (15:85), ${ }^{7}$ transferred to a weighed liter flask, diluted to approximately 1 liter, and again weighed. The waight of the solution was $999.61 \mathrm{~g}$. One gram, therefore, contained U.009509 g of silver phosphate, which is equivalent to $0.002529 \mathrm{~g}$ of magnesium pyrophosphate. All stoichiometric computations were based on the 1925 International Atomic Weights.

\section{(a) TESTS FOR PURITY OF THE REAGENTS AND OF SILVER PHOSPHATE}

Tests for purity of the reagents and of silver phosphate were as follows: The silver nitrate showed no chloride when it was dissolved and slightly acidified with nitric acid. In neutral solution no precipitate formed, thus showing the absence of arsenic and vanadium. The disodium hydrogen phosphate showed no trace of chloride when tested with silver nitrate in dilute nitric acid solution. Tests with hydrogen peroxide in nitric acid solution showed that vanadium was absent. A test with potassium thiocyanate in dilute acid solution showed the absence of iron. The absence of a precipitate after the neutral solution had stood for 12 hours indicated freedom from any appreciable amount of aluminum. Saturation with hydrogen sulphide in either acid or ammoniacal solution gave neither a precipitate nor a coloration. The tests of silver nitrate and disodium hydrogen phosphate were made on $10 \mathrm{~g}$ samples.

The silver phosphate showed no trace of nitrates when tested with diphenylamine and no chloride when it was dissolved in dilute nitric acid and treated with silver nitrate. The residue insoluble in dilute nitric acid mentioned by Baxter and Jones was visible, but amounted to only $0.4 \mathrm{mg}$ in a $2.0 \mathrm{~g}$ sample.

\section{ANALYSIS OF SILVER PHOSPHATE}

(a) DETERMINATION OF SILVER AS CHLORIDE

Portions of the solution of silver phosphate were transferred to beakers by means of weight burettes, and the silver was precipitated by adding hydrochloric acid in such excess that the solution contained 1 per cent of the acid by volume $(1 \mathrm{ml}$ of $\mathrm{HCl}$, specific gravity 1.19 , per $100 \mathrm{ml}$ of solution). The precipitates were coagulated by digesting on the steam bath for one-half hour, after which the solution was cooled and allowed to stand overnight. The precipitates were collected in perforated platinum crucibles fitted with platinum pads (Munroe rucibles), washed with dilute hydrochloric acid (1:99), dried at $140^{\circ} \mathrm{C}$., cooled, and weighed. The filtrates and washings showed not the slightest turbidity. The precipitates showed no occlusion of phosphate. In all operations involving the preparation

7 This denotes $15 \mathrm{ml}$ of concentrated nitric acid (specific gravity 1.42) mixed with $85 \mathrm{ml}$ of water. This system of designating dilute acids is used throughout this paper. If no dilution is specified, the concentrated reagent is intended. Ammonium hydroxide $(1: 19)$ denotes 1 volume of $\mathrm{NH}_{1} \mathrm{OH}$ (specific gravity $0.90)$ mixed with 19 volumes of water, 
of silver phosphate and the precipitation of silver chloride the solutions and precipitates were carefully protected from light. ${ }^{8}$

Table 1 shows the results obtained in the determination of silver in the standard solution of silver phosphate.

TABLE 1.-Results found in determinations of silver in silver phosphate

\begin{tabular}{|c|c|c|}
\hline & \multicolumn{2}{|c|}{$\mathrm{AgCl}$} \\
\hline & $\begin{array}{c}\text { Calculated } \\
\text { from } \\
\text { weight of } \\
\mathrm{Ag}_{3} \mathrm{PO}_{4}\end{array}$ & Found \\
\hline $\begin{array}{l}1 \\
2 \\
3 \\
4 \\
5\end{array}$ & $\begin{array}{r}g \\
0.7018 \\
.7681 \\
.7844 \\
.7648 \\
1.2352\end{array}$ & $\begin{array}{r}g \\
0.7020 \\
.7678 \\
.7844 \\
.7645 \\
1.2352\end{array}$ \\
\hline
\end{tabular}

(b) DETERMINATION OF PHOSPHORUS BY THE PYROPHOSPHATE METHOD (RECOMMENDED PROCEDURE)

The conditions under which phosphorus must be precipitated by magnesia mixture so as to obtain a residue of the correct composition upon ignition have been described by the authors ${ }^{9}$ and by Epperson. ${ }^{10}$ The results obtained, however, were not checked against carefully prepared standards as is done in the present work. The recommended procedure is as follows: To the neutral or faintly acid solution of phosphorus as orthophosphate, containing $0.2 \mathrm{~g}$ of $\mathrm{P}_{2} \mathrm{O}_{5}$ or less, add 5 to $10 \mathrm{ml}$ of hydrochloric acid. Adjust the volume of the solution to 125 to $150 \mathrm{ml}$, and add $10 \mathrm{ml}$ of acid magnesia mixture ${ }^{11}$ per decigram of $\mathrm{P}_{2} \mathrm{O}_{5}$, never less than $10 \mathrm{ml}$ in the first precipitation, cool in ice water, and add ammonium hydroxide slowly and with vigorous stirring until the solution is slightly alkaline to litmus. Stir for a few minutes or until the precipitate is well formed, and then add 5 to $10 \mathrm{ml}$ of ammonium hydroxide. Let stand for at least four hours, preferably overnight, filter, and wash with dilute ammonium hydroxide (1:19). Dissolve the precipitate in $50 \mathrm{ml}$ of warm dilute hydrochloric acid (1:9), wash the paper thoroughly with hot dilute hydrochloric acid (1:99), dilute the solution to 125 to $150 \mathrm{ml}$, add 1 to $3 \mathrm{ml}$ of acid magnesia mixture, cool in ice water, and again precipitate the phosphate by the above procedure. Allow to stand for 4 to 24 hours, filter on a paper of close texture, and wash with dilute ammonium hydroxide $(1: 19)$. Transfer the precipitate and paper to a weighed platinum crucible, char the paper without flaming, burn off the carbon at a temperature below $900^{\circ} \mathrm{C} .{ }^{12}$ and finally ignite to constant weight, preferably in a muffle, at $1,050^{\circ}$ to $1,100^{\circ} \mathrm{C} .^{13}$

8 That this is necessary is shown in an article on The Effect of Light on Silver Chloride in Chemical Analyses, by G. E. F. Lundell and J. I. Hoflman, B. S. Jour. Research, 4 p. 109; 1930.

0 Ind. Fng. Chem., 15, pp. 44 and 171; 1923; and J. Assoc. Official Agri. Chem., s, p. 184; 1924.

10 See footrote 3, p. 280 .

11 Acid magnesia mixture is prepared as follows: Dissolve $50 \mathrm{~g}$ of $\mathrm{MgCl}_{2} \cdot 6 \mathrm{H}_{2} \mathrm{O}$ and $100 \mathrm{~g}$ of $\mathrm{NH}_{4} \mathrm{Cl}$ in $500 \mathrm{ml}$ of water, make slightly ammoniacal, allow to stand overnight, and filter. Acidify the filtrate with hydrochloric acid, add $5 \mathrm{ml}$ of the acid in excess, and diluto to 1 liter.

12 K. D. Jacob and D. S. Reynolds, J. Assoc. Official $\Lambda$ gri. Chem., 11, p. 128; 1928; have shown that phosphorus is lost if $\mathrm{Mg}_{2} \mathrm{P}_{2} \mathrm{O}_{7}$ is ignited with carbon at or above $900^{\circ} \mathrm{C}$.

13 If precipitates are not too large $(<0.25 \mathrm{~g})$ and have been obtained by the recommended procedure, satisfactory results can be had by igniting at $1,000^{\circ} \mathrm{C}$., but then a somewhat longer period of heating is required. For cxample, two precipitates of magnesium ammonium phosphate which theoretically should have yielded residues weighing $0.2421 \mathrm{~g}$ each yielded 0.2420 and $0.2423 \mathrm{~g}$, respectively, on ignition for three lours at $1,000^{\circ} \mathrm{C}$. However, precipitates of twice this weight did not come to constant weight in five hours at the same temperature. 
Table 2 shows the results of determinations of phosphorus in the standard solution of silver phosphate. The procedure just described was followed unless otherwise stated. The silver chloride which formed in the acid solution prior to the first precipitation dissolved when the solution was made ammoniacal, but a little of it may have remained. This was entirely eliminated in the second precipitation.

TABLE 2.-Results obtained by precipitaling phosphorus as $\mathrm{MgNH}_{4} \mathrm{PO}_{4} \cdot 6 \mathrm{H}_{2} \mathrm{O}$ and weighing as $\mathrm{Mg}_{2} \mathrm{P}_{2} \mathrm{O}_{7}$

[Final volume in all precipitations $=150 \mathrm{ml}$ ]

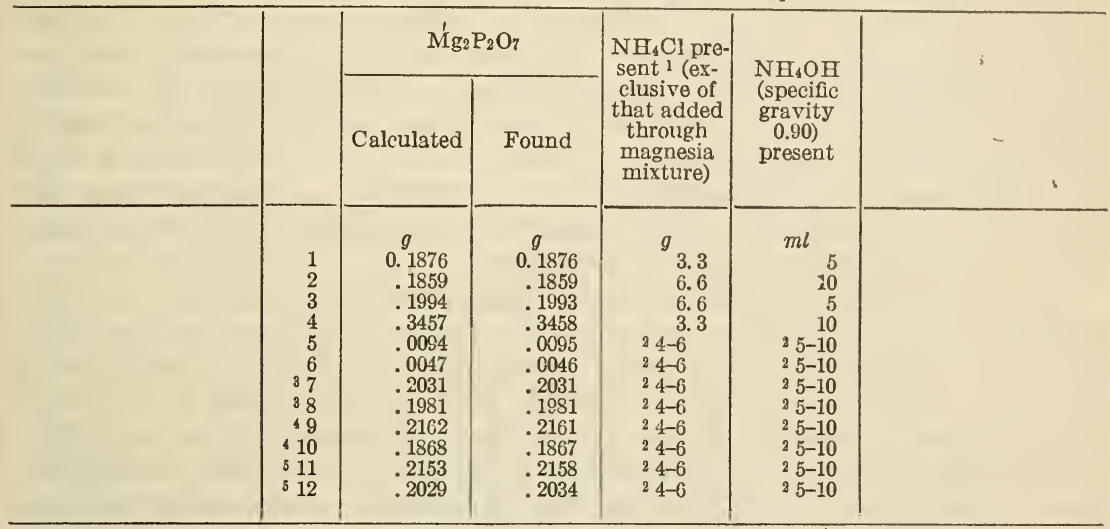

1 This represents the ammonium chloride formed by the neutralization of the acid present in the solution.

2 Between amounts given.

3 Results obtained by applying the method to the filtrates and washings after precipitating the silver as chloride (Nos. 3 and 4 in Table 1 ).

4 Results obtained by precipitating with molybdate reagent as is custcmary in rock analysis, dissolving the precipitate in $\mathrm{NH}_{4} \mathrm{OH}$, acidifying, and then applying the method as written.

8 Silver was removed as in ${ }^{3}$, but only 1 precipitation of magnesium ammonium phosphate was made.

The results in Table 2 were corrected for the solubility of magnesium ammonium phosphate and for the loss in weight of the platinum crucibles. The ignited precipitates were tested for silver and silica, but neither was found. No molybdenum was found in Nos. 9 and 10.

Gooch and Austin ${ }^{14}$ and Epperson ${ }^{15}$ have shown that large amounts of ammonium hydroxide or ammonium chloride are objectionable. The quantity of the latter can not always be controlled in the first precipation but is easily controlled in the second. The conditions outlined in the method can easily be met. In accurate work the second precipitation should be made because results by a single precipitation are usually high and can be correct only as a matter of chance, and then usually through compensating errors. In applied analyses the precipitation is not attempted until the phosphorus has been freed from other substances, such as arsenates or iron, that would also be precipitated. In applied analyses the positive errors obtained in single precipitations are usually more pronounced than is shown in Nos. 11 and 12 in Table $2 .{ }^{16}$

Directions which call for precipitations in hot ${ }^{17}$ or neutral (pH about 7$)^{18}$ solutions are usually recommended as eliminating the

14 See footnote 2, p. 280.

15 See footnote 3 , p. 280 .

16 For a discussion of single and double precipitations see The Analysis of Phosphate Rock, by G. E. F.

Lundell and J. I. Hofiman, J. Assoc. Official A gri. Chem., 8, p. 181; 1924.

17 Gunner Jörgensen, The Analyst, 51, No. 599, p. 61; 1926.

18 Wolcott Gibbs, Am. J. Sci. (3), 5, p. 114; 1873; and McCandless and Burton, Ind. Eng. Chem., 16, p. $1267 ; 1924 ; 19$, p. $406 ; 1927$. 
necessity of a second precipitation. These shorter methods some times take as much of the analyst's time as is required by a second precipitation, and in the end the results are uncertain. For example, by the method of Jörgensen (single precipitation) in which the magnesia mixture is added dropwise to a hot ammoniacal solution of the phosphate and the solution then allowed to stand for four hours, 0.0806 and $0.0809 \mathrm{~g}$ of magnesium pyrophosphate were obtained from aliquot portions $(50.00 \mathrm{ml}$ each) of a solution of phosphoric acid. By applying the recommended procedure (double precipitation) described above, which has been shown to give the correct result, 0.0799 and $0.0798 \mathrm{~g}$ of magnesium pyrophosphate were obtained from similar aliquot portions. By using Jörgensen's method for the first precipitation and the recommended procedure for the second, excepting that in the second precipitation the solution was heated to boiling before the ammonium hydroxide was added, 0.0798 and 0.0798 $\mathrm{g}$ of magnesium pyrophosphate were obtained. In the last case the solution was cooled in ice water after the precipitate had settled, and it was then allowed to stand overnight.

(1) Solubility of Magnesium Ammonium Phosphate in the Determination of Phosphorus.-In order to determine the solubility of magnesium ammonium phosphate under the conditions of operation recommeded, ferric chloride $(0.1 \mathrm{~g})$ was added to the combined filtrates and washings from three determinations of phosphorus made by the recommended procedure. As each determination included two precipitations, the phosphorus represents that lost in six precipitations. The iron and phosphorus were precipitated with a slight excess of ammonium hydroxide, filtered, and the phosphorus then determined in a nitric-acid solution of the precipitate by adding molybdate reagent, filtering, washing, and titrating with alkali. Phosphorus equivalent to $0.0007 \mathrm{~g}$ of $\mathrm{Mg}_{2} \mathrm{P}_{2} \mathrm{O}_{7}$ was found. This amounts to about $0.0001 \mathrm{~g}$ of $\mathrm{Mg}_{2} \mathrm{P}_{2} \mathrm{O}_{7}$ for each precipitation and is significant only in determinations of such small amounts of phosphorus as are found in steels and similar materials.

(2) Ignition of Magnesium Ammonium Phosphate in the Determination of Phosphorus.- In most of the determinations of phosphorus that were made the crucibles containing the moist papers and precipitates were placed in a cold platinum wound electric muffle furnace. The current was then turned on and the temperature allowed to rise to $1,050^{\circ} \mathrm{C}$. in the course of about two hours. In most cases ignition at $1,050^{\circ}$ to $1,100^{\circ} \mathrm{C}$. for one hour yielded residues that did not change in weight on further ignition in the same range, and in very few cases was it necessary to ignite for more than two hours at $1,050^{\circ}$ to $1,100^{\circ} \mathrm{C}$. to obtain constant weight. The residues were entirely free from carbon.

The use of temperatures above $1,100^{\circ} \mathrm{C}$. is not advisable. W. F. Hillebrand ${ }^{19}$ recommends a moderate blast giving a temperature less than $1,100^{\circ} \mathrm{C}$. During the analysis of a phosphate rock one of the authors $(\mathrm{H})$ obtained results for phosphorus which varied more than could be attributed to the ordinary sources of analytical errors. Méker, Fischer, and Tirrill burners had been used in the ignitions. As will be shown below, the variations may have been caused by losses in weight of either or both the crucibles or their contents.

10 U. S. Geol. Surv. Bull., No. 700, p. 150. 
In order to determine the maximum temperatures that could be obtained inside of a crucible by the use of these burners thermocouple wires were welded to the bottom on the inside of a platinum crucible, and the leads up the side of the crucible were insulated by surrounding them with silica tubes. The crucible was covered, and the burners were applied so as to give the maximum heat. The particular burners and gas tested (Washington, D. C., carbureted water gas) gave the following temperatures: Tirrill, $1,165^{\circ} \mathrm{C}$.; Méker, $1,205^{\circ} \mathrm{C}$.; Fischer, $1,240^{\circ} \mathrm{C}$. The data given in Table 3 show thai errors may result from prolonged ignition over any of the burners mentioned. A good blast lamp may give temperatures higher than $1,300^{\circ} \mathrm{C}$. in a covered platinum crucible. A blast lamp should, therefore, never be used in the ignition of magnesium pyrophosphate unless it is certain that the temperature inside of the crucible can not exceed $1,100^{\circ} \mathrm{C}$.

A platinum-wound electric muffle furnace with pyrometer is ideal for such ignitions, because the temperature can be controlled, the heat is evenly distributed throughout the crucible, and drafts and contaminations from gas burners are avoided. In many tests made by us none of the residues showed any visible carbon after ignition for one hour at $1,050^{\circ}$ to $1,100^{\circ} \mathrm{C}$. in the electric muffle furnace. Ignition at the full heat of a Tirrill or Fischer burner for as long as six hours often yields a residue which looks perfectly white on the surface and yet contains a black core. If ignitions are prolonged, the loss in weight of platinum crucibles must be taken into account.

The behavior of properly prepared pyrophosphates heated at different temperatures and the losses in weight of platinum-iridium crucibles are shown in Table 3. All of the temperatures of ignition reported in this and subsequent tables were measured with a platinum to platinum-10 per cent rhodium thermocouple connected to a high resistance millivoltmeter. This pyrometer was calibrated both before and after the investigation, the maximum difference between the two calibrations being $7^{\circ} \mathrm{C}$. The furnace was explored for temperature differences, a maximum of $18^{\circ} \mathrm{C}$. being found in the space used. The thermocouple was placed in an intermediate position. Taking into consideration the temperature differences in the furnace and the $10^{\circ} \mathrm{C}$. accuracy certified for the pyrometer, it is believed that the temperatures of ignition reported are accurate within $\pm 25^{\circ} \mathrm{C}$. The empty crucible used as a blank was originally made from platinum containing 0.7 to 0.8 per cent of iridium. Emf measurements made by $\mathrm{E}$. Wichers indicate that the composition was essentially the same at the time the experiments were made. The crucibles used in Nos. 2, 3, 4 and the blank were of the same lot, and all had been in use for at least 10 years. After dissolving the fused mass in the crucible used in No. 1, washing it out with water, igniting, and weighing, the crucible showed a loss of $0.0026 \mathrm{~g}$ as compared with its weight before the ignitions. The fused pyrophosphate, however, had attacked the platinum. By precipitating the platinum in the hydrochloric-acid solution of the fused mass with hydrogen sulphide and igniting the sulphide to metal, $0.0010 \mathrm{~g}$ of platinum was recovered. The loss through volatilization, therefore, was $0.0016 \mathrm{~g}$. 
TABLE 3.-Ignition of $\mathrm{Mg}_{2} \mathrm{P}_{2} \mathrm{O}_{7}$ in the determination of phosphorus

\begin{tabular}{|c|c|c|c|c|c|c|c|}
\hline & \multirow{2}{*}{$\begin{array}{l}\text { Duration and temper- } \\
\text { ature of ignition (ig- } \\
\text { nitions in sequence) }\end{array}$} & \multicolumn{4}{|c|}{ Weight of ignited residues } & \multirow{2}{*}{$\begin{array}{l}\text { Weight } \\
\text { of empty } \\
\text { platinum } \\
\text { crucible } \\
\text { used as a } \\
\text { blank }\end{array}$} & \multirow{2}{*}{ Remarks } \\
\hline & & No. 1 & No. 2 & No. 3 & No. 4 & & \\
\hline 1 & Constant weight at & $0 . \stackrel{g}{1876}$ & 0.0094 & $\stackrel{g}{g}$ & 0. $\stackrel{g}{g} 982$ & 27. $\stackrel{g}{0911}$ & Ignited residue looked normal. \\
\hline 2 & 1 hour at $1,100^{\circ}$ C. 1 & .1876 & .0094 & .2154 & .1982 & 27.0911 & Do. \\
\hline 3 & 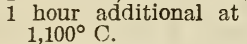 & .1876 & .0093 & .2154 & .1982 & 27.0910 & Do. \\
\hline 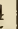 & 1 hour at $1,150^{\circ} \mathrm{C}$ & .1876 & .0092 & .2151 & .1979 & 27. 0909 & Do. \\
\hline 5 & 1 hour at $1,200^{\circ} \mathrm{C}$ & .1875 & .0089 & .2148 & .1976 & 27. 0907 & Do. \\
\hline ? & 1 hour at $1,250^{\circ} \mathrm{C}-\mathrm{C}^{\circ}$ & $\cdot .1873$ & .0084 & .2143 & .1974 & $\begin{array}{l}27.0904 \\
27.0900\end{array}$ & Ignited residue snrank. \\
\hline 3 & 1 hour at $1,400^{\circ} \mathrm{C}$ & .1800 & .0062 & .2085 & .1898 & 27. 0893 & Ignited residue fused to a glass. \\
\hline 9 & $\begin{array}{l}\text { Theoretical weight of } \\
\mathrm{Mg}_{2} \mathrm{P}_{2} \mathrm{O}_{7} \text { as calcu- } \\
\text { lated from } \mathrm{Ag}_{3} \mathrm{PO}_{4} \text {. }\end{array}$ & .1876 & .0094 & .2153 & .1982 & & \\
\hline
\end{tabular}

1 A precipitate, weighing $0.1859 \mathrm{~g}$ after ignition to constant weight at $1,050^{\circ} \mathrm{C}$., was ignited for 3 hours at $1,100^{\circ} \mathrm{C}$. and lost $0.2 \mathrm{mg}$. An empty platinum crucible ignited in the same way lost the same amount.

$2 \mathrm{~A}$ precipitate, weighing $0.3459 \mathrm{~g}$ after ignition to constant weight at $1,050^{\circ} \mathrm{C}$., was ignited for 1 hour at $1,300^{\circ} \mathrm{C}$, and lost $1.9 \mathrm{mg}$. The control crucible ignited in the same way lost $0.4 \mathrm{mg}$.

\section{DETERMINATION OF MAGNESIUM}

Gooch .and Austin ${ }^{20}$ have studied the effect of varying the concentrations of ammonium hydroxide and ammonium chloride during the precipitation of magnesium ammonium phosphate. They used a solution of magnesium nitrate which had been standardized by evaporating portions of the solution with sulphuric acid, igniting at a dull red heat, and weighing the magnesium as sulphate, $\mathrm{MgSO}_{4}$. Epperson ${ }^{21}$ used a solution of magnesium chloride which was standardized by evaporating measured portions with a suspension of mercuric oxide and then igniting to oxide.

\section{PREPARATION OF A SOLUTION OF MAGNESIUM CHLORIDE}

A solution of magnesium chloride was prepared by dissolving the purest available salt in dilute hydrochloric acid $(1: 500)$. The following tests for purity were made: No barium or strontium was found when sulphuric acid was added to a slightly acid $(0.5 \mathrm{ml}$ of $\mathrm{HCl}$ per $100 \mathrm{ml}$ ) solution of $5 \mathrm{~g}$ of the salt. No hydrogen sulphide metals were found in $5 \mathrm{~g}$ of the salt when hydrogen sulphide was passed into either the slightly acid or ammoniacal solution.

The following test for alkalies was applied: Ignite $2.0 \mathrm{~g}$ of the salt $\left(\mathrm{MgCl}_{2} \cdot 6 \mathrm{H}_{2} \mathrm{O}\right)$ for one hour at about $600^{\circ} \mathrm{C}$. to expel the water and most of the chloride, transfer the residue to an agate mortar, and mix thoroughly with $0.4 \mathrm{~g}$ of resublimed ammonium chloride and $4.0 \mathrm{~g}$ of calcium carbonate which has been especially prepared for the determination of alkalies. Determine alkalies by the usual J. Lawrence Smith method, but use a saturated solution of calcium hydroxide in washing the insoluble residue during the extraction of the sintered mass. ${ }^{22}$ Blanks on the reagents must be carried through all

${ }^{20}$ F. $\Lambda$. Gooch and Martha Austin, Am. J. Sci., 4th series, 7, p. 187; 1899; Chem. News, 79, pp. 233 and 244; 1899; Z. anorg. Chem., 20, p. 121; 1899.

21 See footnote 3 , p. 280.

${ }_{22}$ G. E. F. Lundell and H. B. Knowles, The Analysis of Soda Lime Glass, J. Am. Ceram. Soc., 10, p. 828 ; 
steps $0:$ the determination. The average weight of the alkali chlorides obtained in two determinations was $0.2 \mathrm{mg}$ greater than the average weight obtained in two blanks.

As a matter of convenience tests for phosphorus and calcium were applied to the magnesium oxide obtained in the determination of magnesium by weighing as the oxide.

\section{STANDARDIZATION OF THE SOLUTION OF MAGNESIUM CHLORIDE}

The magnesium in the solution of magnesium chloride was determined by (a) weighing as the oxide, $\mathrm{MgO},(b)$ weighing as the sulphate, $\mathrm{MgSO}_{4}$, and (c) weighing as the pyrophosphate, $\mathrm{Mg}_{2} \mathrm{P}_{2} \mathrm{O}_{7}$. The last is the method under observation, and its use is not strictly permissible as a part of the standardization. It is included here because of convenience of comparison. In Tables 4 to 7 , inclusive, the results obtained by the first two methods are taken as the standard.

\section{(a) DETERMINATION OF MAGNESIUM BY WEIGHING AS THE OXIDE}

Weighed portions of the solution were evaporated in platinum crucibles with a suspension of mercuric oxide and then ignited to constant weight at $1,150^{\circ}$ to $1,250^{\circ} \mathrm{C}$. The treatment with mercuric oxide and the ignition were repeated until the weight checked the one obtained after the previous treatment. It is rather difficult to obtain constant weight. This is probably due, at least in part, to the occlusion of gases by magnesium oxide. ${ }^{23}$ The ignited magnesia was tested for phosphorus by dissolving it in nitric acid and adding molybdate reagent. No phosphorus was found. Addition of silver nitrate to the nitric acid solution of one of the precipitates showed that no chloride was left in the ignited oxide. No calcium was found when one of the precipitates was dissolved in dilute sulphuric acid, and alcohol added so that the ratio of sulphuric acid:water alcohol was 1:9:90. Addition of barium chloride to the dilute hydrochloric acid solution of one of the ignited precipitates revealed no sulphate. No mercury was found in the ignited residue.

\section{(b) DETERMINATION OF MAGNESIUM BY WEIGHING AS THE SULPHATE}

Weighed portions of the solution of magnesium chloride were treated in a platinum crucible with $1 \mathrm{ml}$ of sulphuric acid, evaporated to dryness in a radiator, and ignited to constant weight in a muffle at $700^{\circ}$ to $750^{\circ} \mathrm{C}$. The treatment with sulphuric acid and the ignition to constant weight were repeated. The results after the second treatment were the same as those after the first and did not change when the residues were treated with water, evaporated, and again ignited.

(c) DETERMINATION OF MAGNESIUM BY WEIGHING AS THE PYROPHOSPHATE (RECOMMENDED PROCEDURE)

The following procedure is recommended: To the nearly neutral solution containing $0.10 \mathrm{~g}$ or less of magnesia add 5 to $10 \mathrm{ml}$ of hydrochloric acid, and adjust the volume of the solution to 125 to $150 \mathrm{ml} .{ }^{24}$

${ }_{23}$ T. W. Richards and E. F. Rogers, Am. Chem. J., 15, p. 567; 1893; state that the oxide of magnesium retains on ignition sufficient occluded nitrogen and oxygen to increase the weight sensibly.

${ }_{24}$ In applied analyses salts may be in such concentration that they separate at this point, or subsecuently when the solution is rendered ammoniacal. There is no objection in such analyses to making the first precipitation in a greater volume (250 to $400 \mathrm{ml})$; or the solution may be evaporated to dryness, the ammonium salts expelled by gentle ignition, and the residue dissolved in acid and water. 
Cool the solution in ice water, add $10 \mathrm{ml}$ of a freshly prepared solution of diammonium phosphate $\left(\mathrm{NH}_{4}\right)_{2} \mathrm{HPO}_{4}(25 \mathrm{~g}$ of the salt per $100 \mathrm{ml}$ of water), then ammonium hydroxide slowly and with stirring until the solution is alkaline to litmus. Stir for a few minutes, then add 5 to $10 \mathrm{ml}$ of ammonium hydroxide, and stir for a few minutes more. Allow the solution to stand for at least four hours, preferably overnight, then filter on a paper of close texture and wash with dilute ammonium hydroxide (1:19). Dissolve the precipitate in $50 \mathrm{ml}$ of warm dilute hydrochloric acid (1:9), wash the paper thoroughly with hot dilute hydrochloric acid $(1: 99)$, dilute the solution to 125 to $150 \mathrm{ml}$, add $1 / 2$ to $1 \mathrm{ml}$ of the solution of diammonium phosphate, cool in ice water, and again precipitate the magnesium by the above procedure. Allow to stand for 4 to 24 hours, filter on a paper of close texture, and wash with dilute ammonium hydroxide $(1: 19)$ as before. Transfer the precipitate and paper to a weighed platinum crucible, char the paper without flaming, burn off the carbon at a temperature below $900^{\circ} \mathrm{C}$., and finally ignite to constant weight, preferably in a muffle, at $1,100^{\circ} \mathrm{C} .{ }^{25}$ In applied analyses the precipitation of magnesium must, of course, follow the separation of other substances that would be precipitated in an ammoniacal solution containing phosphate. ${ }^{26}$

The results that were obtained by the three methods $(a, b$, and $c$ ) are given in Table 4. Because of the fact that there is a possibility of occluding gases in ignited magnesia, it is believed that in the standardization of the solution the result obtained by ignition as sulphate is to be preferred.

TABLE 4.-Results obtained in the standardization of a solution of magnesium chloride

(The results are given in terms of the weight of $\mathrm{MgO}$ per gram of solution)

\begin{tabular}{|c|c|c|c|}
\hline & \multicolumn{3}{|c|}{ Weight of $\mathrm{MgO}$ found by- } \\
\hline . & $\begin{array}{c}\text { Treating with } \\
\text { HgO and } \\
\text { weighing as } \\
\text { MgO }\end{array}$ & $\begin{array}{c}\text { Treating with } \\
\mathrm{H}_{2} \mathrm{SO}_{4} \text { and } \\
\text { weighing as }^{\mathrm{MgSO}_{4}}\end{array}$ & $\begin{array}{c}\text { Precipitating as } \\
\mathrm{MgNH}_{4} \mathrm{PO}_{4}{ }^{\circ} \\
6 \mathrm{H}_{2} \mathrm{O} \text { and } \\
\text { weighing as } \\
\mathrm{Mq}_{2} \mathrm{P}_{2} \mathrm{O}_{7} \\
\text { (method } \mathrm{c} \\
\text { above) }\end{array}$ \\
\hline $\begin{array}{l}1 \\
2 \\
3 \\
4 \ldots \ldots\end{array}$ & $\begin{array}{c}g \\
0.005383 \\
.005385 \\
.005386 \\
\end{array}$ & $\begin{array}{r}g \\
0.005380 \\
.005380 \\
.005379\end{array}$ & $\begin{array}{l}g \\
0.005381 \\
.005381 \\
.005379 \\
.005382\end{array}$ \\
\hline A verages... & .005385 & .005380 & .005381 \\
\hline
\end{tabular}

(1) Solubility of Magnesium Ammonium Phosphate in the Determination of Magnesium. - It is difficult to make a direct determination of the solubility of magnesium ammonium phosphate under the conditions which obtain in the determination of magnesium,

${ }^{28}$ If precipitates are not too large $(0.2 \mathrm{~g}$ or less) and have been obtained by the recommended procedure, satisfactory results can be obtained by igniting at $1,000^{\circ} \mathrm{C}$., but then a longer period of heating is usually required. For example, the theoretical weight of pyrophosphate was obtained when precipitates yielding
residues weighing 0.2055 and $0.1155 \mathrm{~g}$ were ignited for five hours at $1,000^{\circ} \mathrm{C}$

26 Moderate amounts of certain elements, such as iron, chromium, titanium, zirconium, or tin need not be removed if ammonium citrate is added, Ind. Eng. Chem., 15, pp. 44 and 171: 1923. Preliminary removals of calcium are usually incomplete. Any calcium that escapes will be precipitated together with maguesium. 
but by the following indirect method it was shown that it is approximately the same as in the case of phosphorus:

By following the recommended procedure, but making five reprecipitations, $0.2542 \mathrm{~g}$ and $0.2687 \mathrm{~g}$ of $\mathrm{Mg}_{2} \mathrm{P}_{2} \mathrm{O}_{7}$ were obtained, respectively, as compared with the theoretical values of $0.2545 \mathrm{~g}$ and $0.2690 \mathrm{~g}$. The results were corrected for the loss in weight of the platinum crucibles. Thus, the results obtained by making a total of six precipitations were only $0.3 \mathrm{mg}$ lower than the theoretical. The tests indicate that the equivalent of no more than $0.0001 \mathrm{~g}$ of $\mathrm{Mg}_{2} \mathrm{P}_{2} \mathrm{O}_{7}$ is lost in each precipitation. While these results can not be regarded as conclusive, they are in accord with other experimental work by the authors.

(2) Ignition of Magnesium Ammonium Phosphate in the Determination of Magnesium.-The same precautions as to slow preliminary ignition, charring of paper, etc., which are necessary in the determination of phosphorus also hold in the determination of magnesium. The ignited precipitates gradually lose weight if they are heated at $1,200^{\circ} \mathrm{C}$. or higher. Table 5 shows the results obtained in such ignitions.

TABLE 5.-Ignition of magnesium ammonium phosphate to the pyrophosphate in the determination of $\mathrm{MgO}$ (double precipitation)

(The precipitates were obtained by the recommended method (III, 2, c, p. 287))

\begin{tabular}{|c|c|c|c|c|c|c|c|c|}
\hline \multirow{2}{*}{ No. } & \multirow{2}{*}{$\begin{array}{l}\text { Time and temperature of } \\
\text { ignition (ignitions in } \\
\text { sequence) }\end{array}$} & \multicolumn{5}{|c|}{ Weights of precipitates 1} & \multirow{2}{*}{$\begin{array}{l}\text { Weight } \\
\text { of empty } \\
\text { platinum } \\
\text { crucible } \\
\text { used as a } \\
\text { blank }\end{array}$} & \multirow{2}{*}{ Remarks } \\
\hline & & No. 1 & No. 2 & No. 3 & No. 4 & No. 5 & & \\
\hline 1 & 1 hour at $1,050^{\circ} \mathrm{C}$. & $\stackrel{g}{g}$ & $\stackrel{g}{0.4058}$ & 0. 2190 & $\stackrel{g}{g}$ & $\stackrel{g}{g}$ & 18.8651 & Ignited residues looked \\
\hline $\begin{array}{l}2 \\
3\end{array}$ & $\begin{array}{l}1 \text { hour at } 1,100^{\circ} \mathrm{C} \\
1 \text { hour additional at } \\
1,100^{\circ} \mathrm{C} \text {. }\end{array}$ & $\begin{array}{l}.2755 \\
.2752\end{array}$ & $\begin{array}{l}.4053 \\
.4052\end{array}$ & $\begin{array}{l}.2186 \\
.2183\end{array}$ & $\begin{array}{l}.4012 \\
.4010\end{array}$ & $\begin{array}{l}.0887 \\
.0886\end{array}$ & $\begin{array}{l}18.8649 \\
18.8648\end{array}$ & $\begin{array}{l}\text { normal } \\
\text { Do. } \\
\text { Do. }\end{array}$ \\
\hline $\begin{array}{l}4 \\
5\end{array}$ & 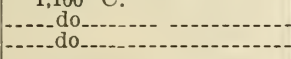 & $\begin{array}{l}.2749 \\
.2748\end{array}$ & $\begin{array}{l}.4051 \\
.4051\end{array}$ & $\begin{array}{l}.2183 \\
.2182\end{array}$ & $\begin{array}{l}.4006 \\
.4005\end{array}$ & $\begin{array}{l}.0885 \\
.0885\end{array}$ & $\begin{array}{l}18.8647 \\
18.8640\end{array}$ & $\begin{array}{l}\text { Do. } \\
\text { Do. }\end{array}$ \\
\hline $\begin{array}{r}6 \\
7 \\
8 \\
9 \\
10\end{array}$ & 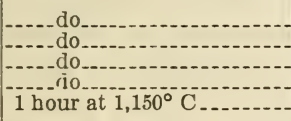 & $\begin{array}{l}.2748 \\
.2749 \\
.2749 \\
.2749 \\
.2749\end{array}$ & $\begin{array}{l}.4050 \\
.4051 \\
.4050 \\
.4050 \\
(3)\end{array}$ & $\begin{array}{l}.2182 \\
.2183 \\
.2183 \\
.2183 \\
.2183\end{array}$ & $\begin{array}{l}.4003 \\
.4003 \\
.4001 \\
.4001 \\
(3)\end{array}$ & $\begin{array}{l}.0884 \\
.0884 \\
.0884 \\
.0884 \\
0.883\end{array}$ & $\begin{array}{l}18.8645 \\
18.8644 \\
18.8643 \\
18.8642 \\
18.8640\end{array}$ & $\begin{array}{l}\text { Do. } \\
\text { Do. } \\
\text { Do. } \\
\text { Do. } \\
\text { Do. }\end{array}$ \\
\hline $\begin{array}{l}11 \\
12 \\
13 \\
14\end{array}$ & $\begin{array}{l}1 \text { hour at } 1,200^{\circ} \mathrm{C} \\
1 \text { hour at } 1,250^{\circ} \mathrm{C}- \\
1 \text { hour at } 1,300^{\circ} \mathrm{C}- \\
\text { Most probable weight of } \\
M \mathrm{~F}_{2} \mathrm{P}_{2} \mathrm{O}_{7} \text { as calculated } \\
\text { from weight of standard } \\
\text { solution taken. }\end{array}$ & $\begin{array}{l}.2749 \\
.2747 \\
.2744 \\
.2748\end{array}$ & $\begin{array}{r}.4044 \\
.4040 \\
(3) \\
.4046\end{array}$ & $\begin{array}{l}.2181 \\
.2181 \\
.2174 \\
.2182\end{array}$ & $\begin{array}{l}.3997 \\
.3993 \\
(3) \\
.3996\end{array}$ & $\begin{array}{l}.0880 \\
.0877 \\
.0871 \\
.0884\end{array}$ & $\begin{array}{l}\text { 18. } 8638 \\
18.8636 \\
18.8631\end{array}$ & $\begin{array}{l}\text { Do. } \\
\text { Ignited residues shrank. } \\
\text { Ignited residues sintered. }\end{array}$ \\
\hline
\end{tabular}

1 These results represent the weights of the precipitates of $\mathrm{Mg}_{2} \mathrm{P}_{2} \mathrm{O}_{7}$, corrected for the loss in weight of the platinum crucibles. At the end of the ignitions the precipitates were brushed out and the empty crucithe platinum crucibles. At the end of the ignitions for No. J lost $0.0018 \mathrm{~g}$ as compared with a loss of $0.0020 \mathrm{~g}$ in the case of the empty crucible used as a blank. These differences in the losses are insignificant when they are distributed over 13 ignitions.

2 This crucible was made of platinum containing about 1.2 per cent of iridium. The cruribles used in the other experiments in this table were of the same lot and had been in use for 5 years. Emf. measurements made by $\mathrm{E}$. Wichers indicate that the present irifium content is about the same as it was originally.

3 Omitted.

The first result is that obtained by slowly igniting in a muffle and then holding the temperature at $1,050^{\circ} \mathrm{C}$. for one hour. The duration and temperature of the subsequent ignitions are those shown in the table.

The data in Table 5 show the following points: (1) Magnesium pyrophosphate obtained in the determination of magnesium by the 
recommended procedure does not lose weight upon prolonged ignition at $1,100^{\circ} \mathrm{C}$. This point is further illustrated in Table 7. ignitions are prolonged, corrections should be made for the loss in weight of platinum crucibles. ${ }^{27}$ (3) At about $1,200^{\circ} \mathrm{C}$. the residue begins to lose weight. The rate of loss increases with increase of temperature. (4) Precipitates yielding $0.3 \mathrm{~g}$ or less of pyrophosphate are more readily ignited to constant weight than larger ones.

An inspection of Table 6 shows that precipitates formed in the presence of a large excess of phosphate require a longer time for ignition to constant weight at temperatures below $1,100^{\circ} \mathrm{C}$. than is required in the case of those formed in the presence of $0.25 \mathrm{~g}$ of diammonium phosphate (the maximum prescribed in the recommended procedure). The positive error is greatest in the case of large precipitates. The weights of the precipitates are corrected for the losses in weight of the platinum crucibles. Excess precipitant has been shown to yield high results in the determination of phosphorus ${ }^{28}$ although there is no particular difficulty in igniting precipitates so obtained to constant weight.

These results emphasize the necessity of making two precipitations and of carefully avoiding a large excess of phosphate in the second. The addition of one-half to $1 \mathrm{ml}$ (equivalent to 0.12 to $0.25 \mathrm{~g}$ of the salt) of the solution of diammonium phosphate in the second precipitation is ample. If two precipitations are not made, there is no convenient way of determining this excess. In Table 6 the results which were obtained by the use of a large excess of phosphate are more accurate than could be expected by a single precipitation in applied analyses, for in the latter the solutions may contain an accumulation of salts that give rise to contamination by compounds, such as $\mathrm{MgNaPO}_{4}$.

The determinations on which Table 7 is based were made in order to compare the behavior on ignition of precipitates of magnesium ammonium phosphate obtained in the determination of phosphorus with those obtained in the determination of magnesium.

The precipitations were made by the recommended methods described above, and the ignitions were made as indicated in the table. During all ignitions the crucibles were placed in the furnace so that they all received essentially the same treatment. Two series of determinations were made. Those in columns $3,4,7$, and 8 were made about two months after the others. The results are corrected for loss in weight of the platinum crucibles. The total loss in weight of the platinum crucible used as a blank with Nos. 3 and 4 was 0.0035 g. The loss in weight of the crucible used as a blank with Nos. 7 and 8 was also $0.0035 \mathrm{~g}$. As this represents a total period of ignition of 40 hours between $1,050^{\circ}$ and $1,200^{\circ} \mathrm{C}$., it shows that a loss of a little less than $0.1 \mathrm{mg}$ per hour is to be expected if the ignition is made in a muffle furnace. ${ }^{29}$

27 Heating in a muffle at $1,100^{\circ} \mathrm{C}$. caused an average loss in weight of about $0.1 \mathrm{mg}$ per hour, but it is not safe to use this correction in all cases, beeause different crueibles may not show the same losses. Ignition over the full heat of a Fischer burner (maximum $1,240^{\circ} \mathrm{C}$. with the gas used) eaused a loss of only $0.3 \mathrm{mg}$ in 18 hours in the ease of an empty erucible used as a eontrol. After this heating the same crueible showed a loss of $0.6 \mathrm{mg}$ in 4 hours in the muffle at $1,100^{\circ} \mathrm{C}$. The empty crucible used to obtain the data in Table 6 when heated for 26 hours at the maxiumm heat of a Fiseher burner lost only 0.4 mg, but subsequent heating in a mumle at $1,100^{\circ} \mathrm{C}$. caused a loss in weight of $0.4 \mathrm{mg}$ in 4 hours.

$28 \mathrm{~J}$. Assoe. Official Agri. Chem., 8, p. 184; 1924.

29 In these experiments platinuni-iridium erucibles (about 0.4 per eent of Ir) were used side by side with platinum-rhodium erucibles (about 3.5 pe: cent of $\mathrm{Rh}$ ), and the behevior of both with respect to loss of weight was about the same. In fact, the empty crueibles used as blanks, one of whieh was made of platinum-iridium and the other of platinum-rhodium, showed exaetly the same loss in weight. 


\begin{tabular}{|c|c|c|c|c|c|c|}
\hline & & & 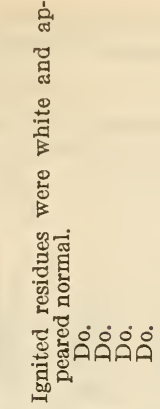 & ஷ்ค่ค் & 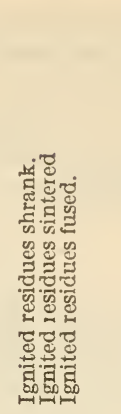 \\
\hline & & \multicolumn{2}{|c|}{ 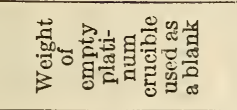 } & 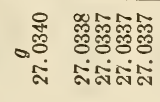 & 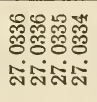 & 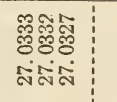 \\
\hline \multirow{11}{*}{ 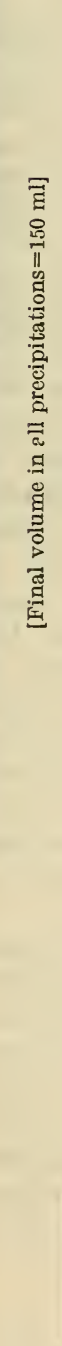 } & \multirow{9}{*}{ 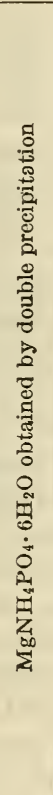 } & \multirow{3}{*}{ 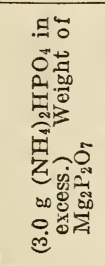 } & m & 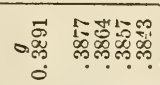 & 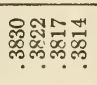 & 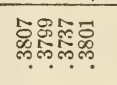 \\
\hline & & & $\begin{array}{l}\text { N } \\
\dot{\mathrm{z}}\end{array}$ & 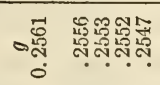 & 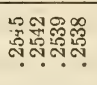 & 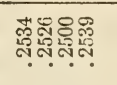 \\
\hline & & & $\ddot{\dot{z}}$ & 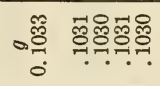 & 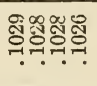 & : \\
\hline & & \multirow{3}{*}{ 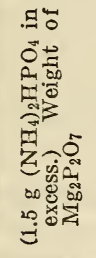 } & @ & 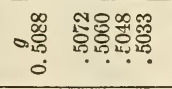 & 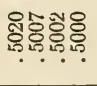 & 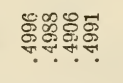 \\
\hline & & & $\stackrel{\sim}{\dot{z}}$ & 蒂 & 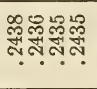 & 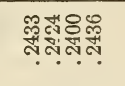 \\
\hline & & & $\ddot{\dot{0}}$ & \multicolumn{2}{|c|}{ 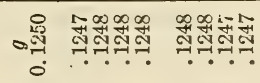 } & : \\
\hline & & \multicolumn{2}{|c|}{ 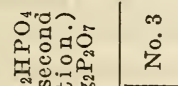 } & 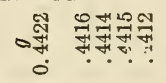 & 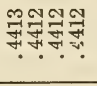 & 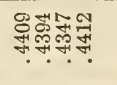 \\
\hline & & 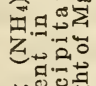 & $\begin{array}{c}\text { N } \\
\dot{z}\end{array}$ & 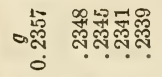 & 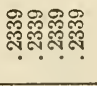 & 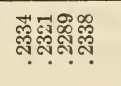 \\
\hline & & 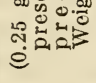 & $\ddot{\dot{0}}$ & 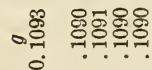 & 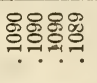 & : \\
\hline & & 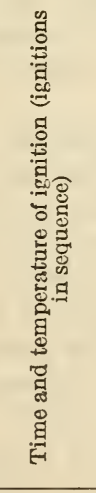 & & 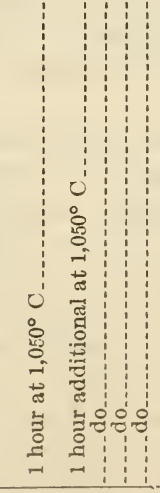 & 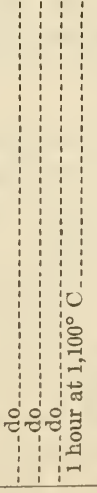 & 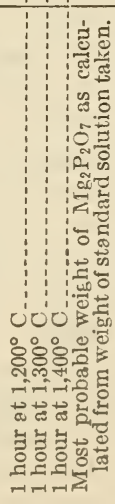 \\
\hline & & $\dot{z}$ & & 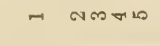 & ondos & ㅇニュの \\
\hline
\end{tabular}


TABLE 7.-Comparative ignitions of precipitates obtained in determinations of magnesium and of phosphorus by the recommended procedures

\begin{tabular}{|c|c|c|c|c|c|c|c|c|c|}
\hline \multirow{2}{*}{ No } & \multirow{2}{*}{$\begin{array}{l}\text { Duration and temperature of } \\
\text { ignitions (ignitions in sequence) }\end{array}$} & \multicolumn{4}{|c|}{$\begin{array}{l}\text { Weight of } \mathrm{Mg}_{2} \mathrm{P}_{2} \mathrm{O}_{7} \text { obtained in } \\
\text { the determination of magnesium }\end{array}$} & \multicolumn{4}{|c|}{$\begin{array}{l}\text { Weight of } \mathrm{Mg}_{2} \mathrm{P}_{2} \mathrm{O}_{7} \text { obtained in } \\
\text { the determination of phosphorus }\end{array}$} \\
\hline & & No. 1 & No. 2 & No. 3 & No. 4 & No. 5 & No. 6 & No. 7 & No. 8 \\
\hline $\begin{array}{l}1 \\
2 \\
3 \\
4 \\
5\end{array}$ & $\begin{array}{l}1 \text { hour at } 1,050^{\circ} \mathrm{C} \\
1 \text { hour additional at } 1,050^{\circ} \mathrm{C} \\
1 \text { hour at } 1,100^{\circ} \mathrm{C} \\
1 \text { hour additional at } 1,100^{\circ} \mathrm{C}\end{array}$ & $\begin{array}{l}g \\
0.2585 \\
.2583 \\
.2575 \\
.2568 \\
.2568\end{array}$ & $\begin{array}{r}g \\
0.2694 \\
.2689 \\
.2682 \\
.2673 \\
.2671\end{array}$ & $\begin{array}{r}g \\
0.2554 \\
.2548 \\
.2548 \\
.2547 \\
.2546\end{array}$ & $\begin{array}{r}g \\
0.2708 \\
.2695 \\
.2696 \\
.2693 \\
.2692\end{array}$ & $\begin{array}{l}g \\
0.2896 \\
.2895 \\
.2894 \\
.2892 \\
.2892\end{array}$ & $\begin{array}{r}g \\
0.2881 \\
.2881 \\
.2880 \\
.2880 \\
.2880\end{array}$ & $\begin{array}{l}g \\
0.4854 \\
.4847 \\
.4847 \\
.4846 \\
.4846\end{array}$ & $\begin{array}{r}g \\
0.2846 \\
.2841 \\
.2281 \\
.2839 \\
.2839\end{array}$ \\
\hline $\begin{array}{r}6 \\
7 \\
8 \\
9 \\
10\end{array}$ & 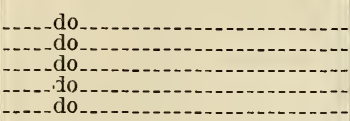 & $\begin{array}{l}.2568 \\
.2566 \\
.2566 \\
.2566 \\
.2566\end{array}$ & $\begin{array}{l}.2671 \\
.2672 \\
.2672 \\
.2672 \\
.2672\end{array}$ & $\begin{array}{l}.2546 \\
.2546 \\
.2546 \\
.2545 \\
.2546\end{array}$ & $\begin{array}{l}.2692 \\
.2691 \\
.2691 \\
.2692 \\
.2692\end{array}$ & $\begin{array}{l}.2892 \\
.2892 \\
.2892 \\
.2892 \\
.2892\end{array}$ & $\begin{array}{l}.2881 \\
.2881 \\
.2881 \\
.2881 \\
.2881\end{array}$ & $\begin{array}{l}.4846 \\
.4846 \\
.4846 \\
.4845 \\
.4845\end{array}$ & $\begin{array}{l}.2839 \\
.2838 \\
.2838 \\
.2838 \\
.2839\end{array}$ \\
\hline $\begin{array}{l}11 \\
12 \\
13 \\
14 \\
15\end{array}$ & $\begin{array}{l}5 \text { hours additional at } 1,100^{\circ} \mathrm{C} \\
1 \text { hour at } 1,200^{\circ} \mathrm{C} \\
1 \text { hour additional at } 1,200^{\circ} \mathrm{C} .\end{array}$ & $\begin{array}{l}.2566 \\
.2555 \\
.2566 \\
.2565 \\
.2564\end{array}$ & $\begin{array}{l}.2672 \\
.2672 \\
.2673 \\
.2671 \\
.2668\end{array}$ & $\begin{array}{l}.2546 \\
.2545 \\
.2546 \\
.2541 \\
.2540\end{array}$ & $\begin{array}{l}.2691 \\
.2691 \\
.2692 \\
.2689 \\
.2688\end{array}$ & $\begin{array}{l}.2892 \\
.2892 \\
.2892 \\
.2890 \\
.2889\end{array}$ & $\begin{array}{l}.2881 \\
.2881 \\
.2881 \\
.2880 \\
.2879\end{array}$ & $\begin{array}{l}.4846 \\
.4846 \\
.4846 \\
.4843 \\
.4843\end{array}$ & $\begin{array}{r}.2839 \\
.2838 \\
.2839 \\
.2835 \\
.2834\end{array}$ \\
\hline $\begin{array}{l}16 \\
17 \\
18 \\
19 \\
20\end{array}$ & 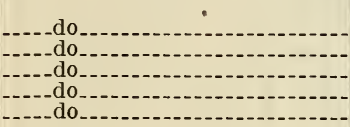 & .2563 & .2666 & $\begin{array}{l}.2540 \\
.2538 \\
.2538 \\
.2537 \\
.2537\end{array}$ & $\begin{array}{l}.2688 \\
.2687 \\
.2687 \\
.2686 \\
.2686\end{array}$ & .2888 & \begin{tabular}{r}
.2878 \\
\hdashline-2 \\
\hdashline-1. \\
\end{tabular} & $\begin{array}{l}.4841 \\
.4838 \\
.4837 \\
.4837 \\
.4836\end{array}$ & $\begin{array}{l}.2833 \\
.2831 \\
.2830 \\
.2830 \\
.2829\end{array}$ \\
\hline $\begin{array}{l}21 \\
22 \\
23 \\
24 \\
25\end{array}$ & $\begin{array}{l}5 \text { hours additional at } 1,200^{\circ} \mathrm{C}_{-} \\
10 \text { hours additional at } 1,200^{\circ} \mathrm{C}_{-} \\
\text {Most probable weight }\end{array}$ & & 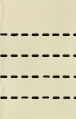 & $\begin{array}{l}.2536 \\
.2535 \\
.2531 \\
.2527\end{array}$ & $\begin{array}{l}.2686 \\
.2684 \\
.2682 \\
.2679\end{array}$ & & 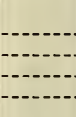 & $\begin{array}{l}.4836 \\
.4835 \\
.4831 \\
.4829\end{array}$ & $\begin{array}{l}.2829 \\
.2828 \\
.2824 \\
.2818\end{array}$ \\
\hline & $\begin{array}{l}\mathrm{Most} \text { probable weight of } \\
\mathrm{Mg}{ }_{2} \mathrm{P}_{2} \mathrm{O}_{7}\end{array}$ & .2567 & .2672 & .2546 & .2691 & .2893 & .2881 & . 4847 & .2840 \\
\hline
\end{tabular}

The data given in Table 7 show that after constant weight is reached the pyrophosphate residues obtained in the determination of magnesium and phosphorus behave similarly upon further ignition. The data also show that constant weight is reached more quickly in the determination of phosphorus than in the determination of magnesium. However, after constant weight was once obtained the results did not change in either case upon prolonged ignition at $1,100^{\circ} \mathrm{C}$... There is a very slow but definite loss in weight if the residues are ignited at $1,200^{\circ} \mathrm{C}$. Residues obtained by gradually heating precipitates to $900^{\circ} \mathrm{C}$. until the carbon was burned off and then heating immediately for periods of one hour at $1,200^{\circ} \mathrm{C}$., showed a behavior upon further ignition at $1,200^{\circ} \mathrm{C}$. similar to that of precipitates which received the prolonged intervening ignition at $1,100^{\circ} \mathrm{C}$. shown in Table 7.

The longer time required for the satisfactory ignition of the precipitate obtained in the determination of magnesium is probably a result of the formation of a compound containing an excess of phosphate, such as $\mathrm{Mg}\left(\mathrm{NH}_{4}\right)_{4}\left(\mathrm{PO}_{4}\right)_{2}$. Upon ignition of this compound magnesium metaphosphate, $\mathrm{Mg}\left(\mathrm{PO}_{3}\right)_{2}$, is formed which causes the result to be slightly high. Longer ignition or ignition at a higher temperature probably converts this compound to the pyrophosphate as follows: $2 \mathrm{Mg}\left(\mathrm{PO}_{3}\right)_{2}=\mathrm{Mg}_{2} \mathrm{P}_{2} \mathrm{O}_{7}+\mathrm{P}_{2} \mathrm{O}_{5}$. A large excess of diammonium phosphate will cause the formation of more of the compound rich in phosphorus and probably accounts for the long period of ignition required in the case of some of the residues in Table 6.

Table 7 also shows that if ignition is prolonged at $1,100^{\circ} \mathrm{C}$. correction must be made for the loss in weight of the platinum crucibles. 
It is worthy of note that the loss in weight of the crucibles during 21 hours of heating at $1,200^{\circ} \mathrm{C}$. was slightly greater than the net loss in weight of the pyrophosphate residues. This means that if the loss in weight of the crucibles had been neglected, the total loss in weight would have been attributed to the pyrophosphate residues and would have been more than twice as great as it was actually shown to be.

\section{SUMMARY}

The conditions necessary for obtaining a final product that has the formula $\mathrm{Mg}_{2} \mathrm{P}_{2} \mathrm{O}_{7}$ in determinations of phosphorus or magnesium are set forth. These conditions were tested by applying the methods as written to carefully prepared standards of reference.

The solubility of magnesium ammonium phosphate in the procedure recommended for the determination of phosphorus is equivalent to approximately $0.0001 \mathrm{~g}$ of $\mathrm{Mg}_{2} \mathrm{P}_{2} \mathrm{O}_{7}$ for each precipitation, including the attendant washing. There is no evidence that it is greater in the determination of magnesium.

The temperature at which magnesium pyrophosphate is ignited deserves more attention than it has received in the past. Ignition to constant weight at $1,100^{\circ} \mathrm{C}$. is recommended in accurate work. At $1,000^{\circ} \mathrm{C}$. constant weight is obtained slowly, particularly with large residues while at $1,200^{\circ} \mathrm{C}$. there is a slow but definite loss in weight. It is more difficult to obtain constant weight in determinations of magnesium than in determinations of phosphorus.

Prolonged ignition in a muffle at temperatures above $1,000^{\circ} \mathrm{C}$. causes appreciable losses in weight of platinum crucibles. It is shown that it is necessary to make corrections for these losses.

The temperatures that can be obtained with three types of burners are given.

Washington, March 7, 1930. 